\title{
Considerations about complicated caries of primary molars
}

\author{
Considerații asupra cariei complicate a molarilor temporari
}

\author{
Ioana-Andreea Stanciu', Mihaela Tănase' ${ }^{1}$, Rodica Luca', \\ Daciana-Diana-Daniela Zmărăndache ${ }^{1}$, Bogdan-Laurențiu lanca' ${ }^{2}$, Aneta Munteanu ${ }^{1}$ \\ ${ }^{1}$ Disciplina de Pedodonție, Facultatea de Medicină Dentară, UMF „Carol Davila“, București, România \\ ${ }^{2}$ Rezidenţiat, București, România
}

\begin{abstract}
Aim. Assessment of the distribution and severity of complicated caries in primary molars and the treatment methods applied in a group of children treated in the Pedodontics Department, Bucharest.

Material and method. Retrospective observational-descriptive study performed on the dental files of 100 patients (48 boys) aged between 3 and 10 years. The inclusion criteria was: at least one second primary molar erupted, in non-syndromic patients caries-free or with common pattern of caries. Caries prevalence index (Ip) and $\mathrm{dmf}-\mathrm{t} / \mathrm{s}$ indices on primary molars for the whole group, by age groups and sex were calculated. Caries distribution and severity, especially those complicated on primary molars and the treatment methods applied were assessed. Statistical analysis was performed with the program SPSS 20.0, using t-test and ANOVA-test $(p=0.05)$.

Results. I $p=95 \% ; 78 \%$ of children had at least one primary molar with complicated caries; dmf-t $=4.02 \pm 2.93$; dmf-s $=9.67 \pm 6.83$. Of the 748 primary molars examined, $394(52.67 \%)$ had caries, of which $242(61.42 \%)-$ uncomplicated caries and 152(38.57\%) - complicated caries: $56(14.21 \%)$ with pulpitis - $12(3.04 \%)$ acute pulpitis and $44(11.16 \%)$ chronic pulpitis, $96(24.36 \%)$ with pulp necrosis - $5(1.26 \%)$ uncomplicated, $91(23.09 \%)$ complicated. $51.01 \%$ of caries were occlusal-proximal, the differences being non-statistically significant between arches $(p>0.05)$. First primary molars were more affected by complicated caries than the second ones $(58.55 \%$ versus $41.45 \%)(p<0.05)$. The most common treatment methods applied: for pulpitis-devital pulpectomy $(88.57 \%)$; for pulp necrosis: conservative treatment $(37.5 \%)$, extraction $(52.08 \%)$.

Conclusions. The high prevalence of complicated caries in primary molars underlines the need for regular dental check-ups in order to apply more conservative treatments.
\end{abstract}

Keywords: primary molars, complicated caries, children

\section{REZUMAT}

Scop. Evaluarea distribuției și gravității proceselor carioase complicate ale molarilor temporari (Mtemp) și a tratamentelor aplicate acestora, la un lot de copii tratați în Clinica de Pedodonție, București.

Material şi metodă. Studiu retrospectiv observațional-descriptiv realizat pe fișele a 100 pacienți (48 băieți) cu vârste între 3 și 10 ani. Criteriile de includere au fost: cel puțin un M2temp prezent pe arcadă, la pacienți nonsindromici indemni de carie sau cu tipar carial obișnuit. S-au calculat: indicele de prevalență a cariei (Ip) și indicii dmf-t/-s la nivelul Mtemp pentru întregul lot, pe grupe de vârstă și sexe. S-au evaluat distribuția și gravitatea cariilor, în special a celor complicate de la nivelul Mtemp, precum și metodele de tratament aplicate. Analiza statistică s-a realizat cu programul SPSS 20.0, folosind t-test și ANOVA-test $(p=0,05)$.

Rezultate. Ip $=95 \%$; $78 \%$ dintre copii au prezentat cel puțin un Mtemp cu carie complicată; dmf-t $=4,02 \pm 2,93$; dmf-s $=9,67 \pm 6,83$. Dintre cei 748 de Mtemp examinați, $394(52,67 \%)$ aveau carii, dintre care $242(61,42 \%)$ - carie simplă și 152(38,57\%) - carie complicată: $56(14,21 \%)$ cu pulpită - 12(3,04\%) pulpite acute și $44(11,16 \%)$ pulpite cronice, $96(24,36 \%)$ cu gangrenă - $5(1,26 \%)$ gangrene simple, $91(23,09 \%)$ gangrene complicate. 51,01\% dintre carii au fost ocluzo-proximale, diferențele fiind nesemnificative statistic între arcade $(p>0,05)$. M1 temp au mai afectați prin carie complicată decât M2temp $(58,55 \%$, respectiv $41,45 \%)(p<0,05)$. Cele mai frecvente metode de tratament au fost: în pulpite - pulpectomia devitală (88,57\%); în gangrenă: tratament conservator $(37,5 \%)$, extracție $(52,08 \%)$. Concluzii. Prevalența crescută a cariei complicate la Mtemp indică necesitatea controlelor stomatologice regulate pentru a putea aplica tratamente cât mai conservatoare. 


\section{INTRODUCERE}

Caria reprezintă cea mai frecventă patologie a dinţilor temporari (DT) şi este un subiect de interes pentru multe studii epidemiologice realizate în întreaga lume [1]. Astfel, un studiu realizat de Kashetty şi colab. în India în 2016 a arătat că la un lot de copii cu vârste de 3-6 ani prevalenţa cariei a fost de 62,14\% [2], iar Elfrink şi colab. (2006) au constatat că $49 \%$ dintre copiii de 5 ani din Olanda aveau carii pe DT [3]. În studii efectuate în România pe loturi de copii cu vârste cuprinse între 3 şi 7 ani, s-au raportat valori ale prevalenţei cariei care au variat de la 61,27\% la Cluj (Cocârlă şi colab., 2003), 65,78\% la Bucureşti (Luca şi colab., 2001) şi 69,49\% la Iaşi (Dorobăţ şi colab., 1994) [4].

Frecvenţa destul de mare a cariei la copiii preşcolari se datorează naturii sale multifactoriale $[5,6]$. Caria DT respectă adesea un tipar specific, cei mai afectaţi fiind molarii mandibulari (în special, cei secunzi) [2]. Formele clinice de îmbolnăvire au caracteristici care derivă din particularităţile morfologice şi de structură ale DT, cele mai frecvente fiind caria simplă profundă, pulpita cronică şi gangrena parţială simplă sau complicată.

În acest context, scopul studiului a fost evaluarea distribuţiei şi gravităţii proceselor carioase complicate ale molarilor temporari, precum şi a metodelor de tratament aplicate la nivelul acestora, la un lot de copii examinaţi şi trataţi într-o clinică universitară.

\section{MATERIAL ŞI METODĂ}

Cercetarea a constat într-un studiu retrospectiv observaţional-descriptiv realizat pe fişele de observaţie ale unor pacienţi diagnosticaţi şi trataţi în Clinica de Pedodonţie a UMF „Carol Davila“ Bucureşti în perioada 2015-2019.
Lotul a fost alcătuit din 100 de pacienţi (48 băieţi) cu vârste cuprinse între 3 şi 10 ani (fig. 1).

Criteriile de includere au fost:

- pacienţi cu vârste mai mari sau egale cu 3 ani, cu cel puţin un M2 temporar prezent pe arcadă

- pacienţi indemni de carie sau cu leziuni carioase cu tipar obişnuit

- pacienţi fără afecţiuni generale asociate (nonsindromici).

Din fişe, s-au înregistrat date cu privire la: vârsta şi sexul pacienţilor, leziunile carioase, tratamentele efectuate.

S-au calculat: indicele de prevalenţă a cariei (Ip) şi indicii de experienţă carioasă dmf-t/-s la nivelul molarilor temporari atât pentru întregul lot, cât şi pe grupe de vârstă şi sexe. De asemenea, s-au evaluat distribuţia şi gravitatea leziunilor carioase, în special a celor complicate de la nivelul molarilor temporari, precum şi metodele de tratament aplicate. Analiza statistică s-a realizat cu programul SPSS 20.0, semnificaţia statistică a diferenţelor dintre medii fiind apreciată cu t-test şi ANOVA, pentru p $=0,05$.

\section{REZULTATE}

\section{Prevalența cariei}

95\% dintre copiii examinaţi au avut leziuni carioase la nivelul molarilor temporari. $78 \%$ au prezentat cel puţin un molar cu carie complicată.

\section{Indicii de experiență carioasă}

Indicii de experienţă carioasă dmf-t şi dmf-s au avut valorile 4,02 $\pm 2,93$ şi, respectiv, $9,67 \pm 6,83$, la băieţi fiind: $\mathrm{dmf}-\mathrm{t}=4,06+2,55$; dmf-s $=8,91 \pm 5,42$, iar la fete: dmf-t $=3,98 \pm 2,25$; dmf-s $=10,36 \pm 7,9$ $(p>0,05)$. Componentele indicilor au fost următoa-

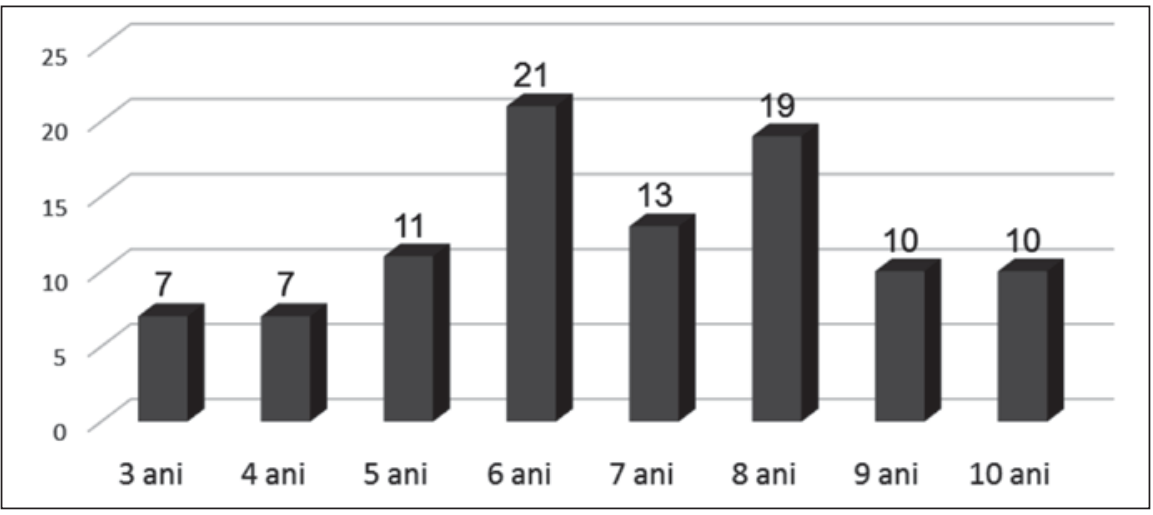

FIGURA 1. Distribuția pe vârste a lotului studiat ( $n=100$ copii) 
TABEL 1. Indicii dmf-t/s în funcție de vârstă

\begin{tabular}{|l|c|c|c|c|c|c|c|c|}
\hline Vârsta (ani) & $\mathbf{3}$ & $\mathbf{4}$ & $\mathbf{5}$ & $\mathbf{6}$ & $\mathbf{7}$ & $\mathbf{8}$ & $\mathbf{9}$ & $\mathbf{1 0}$ \\
\hline $\boldsymbol{d} \boldsymbol{m} \boldsymbol{f}-\boldsymbol{t}$ & $3 \pm 3,1$ & $5 \pm 2,3$ & $5,18 \pm 2,22$ & $5,04 \pm 1,85$ & $3,38 \pm 2,02$ & $3,95 \pm 2,64$ & $3,18 \pm 2,22$ & $2,5 \pm 2,06$ \\
\hline $\boldsymbol{d} \boldsymbol{m} \boldsymbol{f}-\boldsymbol{s}$ & $4 \pm 4,12$ & $10 \pm 4,32$ & $9,81 \pm 4,33$ & $12,19 \pm 6,16$ & $7,38 \pm 5,10$ & $11,95 \pm 9,69$ & $9,27 \pm 6,85$ & $6,8 \pm 5,55$ \\
\hline
\end{tabular}

* $p=0,028$ intre grupele 6 şi 10 ani pentru dmf-t

* $p=0,0061$ intre grupele 3 şi 6 ani pentru dmf-s

rele: $\mathrm{dt}=3,94 \pm 2,36, \mathrm{mt}=0,08 \pm 0,44, \mathrm{ft}=0$; $\mathrm{ds}=9,27 \pm 6,32 \mathrm{~ms}=0,4 \pm 2,21, \mathrm{fs}=0$. Cele mai mari valori ale indicilor de experienţă carioasă s-au întâlnit la copiii cu vârste cuprinse între 4 şi 6 ani (tabel 1).

Studiul fiind realizat pe un lot de copii cu tipar carial obişnuit (carii în special pe molarii temporari, incisivii fiind indemni), valorile obţinute pentru indicii de prevalenţă şi de experienţă carioasă sunt valabile şi pentru întreaga dentiţie temporară.

\section{Distribuția molarilor temporari cariați pe grupe de vârstă şi sexe}

Dintre cei 748 de molari temporari examinaţi, $354(47,52 \%)$ au fost indemni şi $394(52,67 \%)$ au prezentat leziuni carioase. Repartiţia molarilor cariaţi în funcţie de sex a fost aproximativ egală: 49,49\% - băieţi şi 50,51\% - fete $(p>0,05)$. Distribuţia raportată la vârstă a fost următoarea: 21 $(5,33 \%)$ molari cariaţi la 3 ani, $35(8,88 \%)$ la 4 ani, $57(14,47 \%)$ la 5 ani, $106(26,9 \%)$ la 6 ani, 44 $(11,17 \%)$ la 7 ani, $72(18,27 \%)$ la 8 ani, 34 (8,63\%) la 9 ani şi $25(6,35 \%)$ la 10 ani.

\section{Distribuția molarilor temporari în funcție de topografia cariilor}

$51,01 \%$ dintre molari au prezentat carii ocluzoproximale. $\mathrm{Nu}$ au existat diferenţe semnificative statistic între cele două arcade cu privire la topografia proceselor carioase $(p>0,05)($ tabel 2$)$.

\section{Distribuția molarilor temporari în funcție de patologia carioasă}

Dintre cei 394 de molari temporari cariaţi, 242 $(61,42 \%)$ au prezentat carie simplă şi $152(38,57 \%)-$ carie complicată. Distribuţia molarilor cu carie complicată a fost următoarea: $56(14,21 \%)$ au avut variate forme de pulpite - $12(3,04 \%)$ pulpite acute şi $44(11,16 \%)$ pulpite cronice), iar $96(24,36 \%)$ gangrene - $14(3,55 \%)$ gangrene parţiale, 72 $(20,81 \%)$ gangrene totale; $5(1,26 \%)$ gangrene simple, 91 (23,09\%) gangrene complicate: 51 $(12,94 \%)$ - cu parodontite apicale cronice şi 40 $(10,15 \%)$ cu parodontite apicale acute).

$64,47 \%$ dintre molarii cu carii complicate au fost la copiii cu vârste între 6 şi 8 ani, 19,74\% între 3 şi 5 ani şi $15,79 \%$ între 9 şi 10 ani.

Cei mai afectaţi au fost M2temp prin carie simplă $(\mathrm{p}<0,05)$ şi M1temp prin carie complicată $(\mathrm{p}<0,05)($ tab.3).

TABELUL 3. Distribuția molarilor temporari cariați în funcție de poziția pe arcade

\begin{tabular}{|l|c|c|c|c|}
\hline \multirow{2}{*}{ M1 sup } & \multicolumn{2}{|c|}{ Carie simplă } & \multicolumn{2}{c|}{ Carie complicată } \\
\cline { 2 - 5 } & $\mathrm{N}$ & $\%$ & $\mathrm{n}$ & $\%$ \\
\hline M2sup & 71 & 19 & 44 & 28,94 \\
\hline M1inf & 57 & 29,33 & 27 & 17,76 \\
\hline M2inf & 68 & 23,55 & 45 & 18,59 \\
\hline
\end{tabular}

$48,68 \%$ dintre molarii în stadiul II şi $50,65 \%$ dintre cei în stadiul III au fost diagnosticaţi cu carie complicată şi doar $0,65 \%$ dintre cei în stadiul I.

\section{Distribuția molarilor cu carii complicate în funcție de tratamentele aplicate}

Pentru tratamentul cariilor complicate, s-au realizat tehnici de tratament în funcţie de tipul de îmbolnăvire şi de stadiul de dezvoltare a dinţilor, metodele variind de la tehnici conservatoare la teh-

TABEL 2. Distribuția molarilor temporari în funcție de poziția pe arcadă şi de topografia proceselor carioase

\begin{tabular}{|c|c|c|c|c|c|c|c|c|c|c|c|c|}
\hline \multirow[t]{2}{*}{ Dinți } & \multicolumn{2}{|c|}{ Ocluzală } & \multicolumn{2}{|c|}{$\begin{array}{l}\text { Ocluzo- } \\
\text { proximală }\end{array}$} & \multicolumn{2}{|c|}{ Ocluzo-V/P } & \multicolumn{2}{|c|}{3 suprafețe } & \multicolumn{2}{|c|}{4 suprafețe } & \multicolumn{2}{|c|}{ Rest radicular } \\
\hline & $n$ & $\%$ & $\mathrm{~N}$ & $\%$ & $\mathrm{n}$ & $\%$ & $n$ & $\%$ & $n$ & $\%$ & $\mathrm{n}$ & $\%$ \\
\hline M1sup & 10 & 2,58 & 46 & 11,67 & 2 & 0,50 & 10 & 2,53 & 5 & 1,26 & 18 & 4,56 \\
\hline M2sup & 23 & 5,83 & 51 & 12,94 & 5 & 1,26 & 9 & 2,28 & 1 & 0,25 & 9 & 2,28 \\
\hline M1inf & 14 & 3,55 & 56 & 14,21 & 3 & 0,76 & 11 & 2,79 & 5 & 1,26 & 14 & 3,55 \\
\hline M2inf & 27 & 6,85 & 48 & 12,18 & 4 & 1,01 & 9 & 2,28 & 8 & 2,03 & 6 & 1,52 \\
\hline
\end{tabular}


TABEL 4. Distribuția molarilor cu pulpită după stadiul de dezvoltare şi tratamentul aplicat ( $n=96$ dinți)

\begin{tabular}{|l|c|c|c|c|c|c|c|c|c|}
\hline $\begin{array}{l}\text { Stadiu de } \\
\text { dezvoltare } \\
\text { dinte }\end{array}$ & \multicolumn{2}{|c|}{ Pulpotomie } & \multicolumn{2}{|c|}{$\begin{array}{c}\text { Pulpectomie } \\
\text { vitală }\end{array}$} & \multicolumn{2}{c|}{$\begin{array}{c}\text { Pulpectomie } \\
\text { devitală }\end{array}$} & \multicolumn{2}{|c|}{ Extracție } & Total \\
\cline { 2 - 10 } & $\mathrm{n}$ & $\%$ & $\mathrm{n}$ & $\%$ & $\mathrm{n}$ & $\%$ & $\mathrm{n}$ & $\%$ & $\mathrm{n}$ \\
\hline I & 0 & 0 & 1 & 100 & 0 & 0 & 0 & 0 & 1 \\
\hline II & 3 & 8,57 & 1 & 2,85 & 31 & 88,57 & 0 & 0 & 35 \\
\hline III & 2 & 10 & 2 & 10 & 12 & 60 & 4 & 20 & 20 \\
\hline
\end{tabular}

TABEL 5. Distribuția molarilor cu gangrenă după stadiul de dezvoltare şi tratamentul aplicat $(n=96$ dinți)

\begin{tabular}{|l|c|c|c|c|c|c|c|c|c|}
\hline $\begin{array}{l}\text { Stadiu } \\
\text { de } \\
\text { dezvoltare } \\
\text { dinte }\end{array}$ & \multicolumn{2}{|c|}{$\begin{array}{c}\text { Tratament } \\
\text { conservator }\end{array}$} & \multicolumn{2}{|c|}{$\begin{array}{c}\text { Tratament în stilul } \\
\text { unei amputații }\end{array}$} & \multicolumn{2}{|c|}{$\begin{array}{c}\text { Drenaj } \\
\text { continuu }\end{array}$} & \multicolumn{2}{|c|}{ Extracție } & Total \\
\cline { 2 - 10 } & $\mathrm{n}$ & $\%$ & $\mathrm{n}$ & $\%$ & $\mathrm{n}$ & $\%$ & $\mathrm{n}$ & $\%$ & $\mathrm{~N}$ \\
\hline $\mathrm{I}$ & 0 & 0 & 0 & 0 & 0 & 0 & 0 & 0 & 0 \\
\hline II & 25 & 64,10 & 2 & 5,12 & 1 & 2,56 & 11 & 28,20 & 39 \\
\hline III & 11 & 19,29 & 3 & 5,26 & 4 & 7,01 & 39 & 68,42 & 57 \\
\hline
\end{tabular}

nici de compromis sau extracţie. În pulpite, atât la dinţii în stadiul 2, cât şi la cei în stadiul 3, s-au realizat, în majoritatea cazurilor, pulpectomii devitale (tabel 4).

În cazul dinţilor diagnosticaţi cu gangrenă, pentru cei aflaţi în stadiul 2 de dezvoltare s-au efectuat mai frecvent tratamente conservatoare şi pentru cei în stadiul 3 - mai frecvent extracţii (tabel 5).

\section{DISCUȚII}

Multe ţări au dezvoltat diferite strategii pentru a reduce caria dentară la copii, unele dintre ele obţinând rezultate bune prin implementarea unor programe de prevenire bazate pe instruirea privind igiena orală, fluorizarea topică şi controalele stomatologice regulate. Astfel, Azizi şi colab. (2014) [7] au arătat că frecvenţa subiecţilor indemni de carie era în Marea Britanie (2003) de 40-60\% la copiii în vârstă de 5 ani, în Suedia (2003) de 69\% la copiii de 3 ani şi de 66\% în Australia (2002) la copiii de 4-6 ani, în timp ce în Pakistan doar 24\% dintre copiii în vârstă de 4-5 ani erau fără nicio carie. Aceste rezultate antagonice derivă din inegalităţile socio-economice şi de resurse, din diferenţele dintre eficienţa sistemelor publice de sănătate, din motivaţia părinţilor şi a copiilor, din stilurile diferite de viaţă.

Rezultatele studiului prezent arată că, la copiii examinaţi care prezentau carii cu tipar obişnuit, prevalenţa cariei a fost de 95\%. În Polonia, 89,8\% dintre copiii de 7 ani şi, respectiv, $93 \%$ dintre cei de 7-8 ani aveau leziuni carioase pe dinţii tempo- rari (Baginska şi colab., 2014) [8]. În Lituania (2009), prevalenţa cariei la dinţii temporari la 7-8 ani era de 88,7\% (Matulaitiene şi colab., 2012) [9], iar în China, Zhang şi colab. (2014) au raportat la grupa de vârstă 5 ani o frecvenţă de 89\% [10].

Valorile indicilor de experienţă carioasă au fost mari, la întregul lot pacienţii având în medie 4 molari temporari şi 9 suprafeţe dentare afectate prin carie. Cea mai mare contribuţie au avut-o componentele d-t/s: $98 \%$ din indicele dmf-t a fost reprezentat de componenta d-t şi 97,88\% din indicele dmf-s - de componenta d-s. Wyne şi colab. (2008, Arabia Saudită) au raportat un indice dmf-t de $6,1 \pm 3,9$ pentru un lot de copii preşcolari, componenta d-t, cu o valoare de $4,66+3,66$, fiind $76,4 \%$ din indicele dmf-t [11]. Zhang şi colab. (2014, China) au calculat un indice dmf-t de 7,0 pentru 127 de copii de 5 ani, d-t fiind $87 \%$ din indicele dmf-t [10]. Elfrink şi colab. (2006), deşi au găsit un indice dmft mai mic, de 2,5, la copiii de 5 ani din Olanda, au arătat că d-t a reprezentat $80 \%$ din dmf-t [3]. Într-un studiu realizat de Luca şi colab., în 2001, în Bucureşti, România, pe un lot de copii preşcolari cu vârste între 3 şi 7 ani, indicele dmf-t a fost 3,98 $\pm 0,64$, cu dt reprezentând 97,34\% [4]. Kashetty şi colab. (2016, India) au găsit valori mai scăzute ale indicelui dmf-t, anume 2,34 $\pm 2,64$, la copiii cu vârste între 3 şi 6 ani, componenta dt având, însă, tot cea mai mare influenţă, de 99,89\% [2].

Valoarea indicelui dmf-s de 9,67 raportată în studiul prezent a fost apropiată de valoarea de 9,10 găsită de Chandan şi colab. (2018) în India la 500 de copii cu vârste cuprinse între 3 şi 6 ani [12]. 
$\mathrm{Cu}$ privire la distribuţia în funcţie de sex, nu s-au găsit diferenţe semnificative statistic între fete şi băieţi, rezultat similar cu Kashetty şi colab. (2016) [2], dar diferit de Chandan şi colab. (2018), care au constatat diferenţe semnificative statistic pentru dmf-s în favoarea băieţilor $(p=0,009)$ [12].

$\mathrm{S}$-au analizat şi valorile indicilor dmf-t şi dmf-s pe intervale de vârstă, valorile maxime fiind înregistrate între 4 şi 6 ani. Diferenţe semnificative statistic au fost observate doar între grupele de vârstă 6 şi 10 ani pentru indicele dmf-t $(p=0,028)$ şi între grupele 3 şi 6 ani pentru indicele dmf-s $(p=0,0061)$. Kashetty şi colab. (2016) au găsit diferenţe semnificative statistic pentru ambii indici între grupele de vârstă 3, 4, 5 şi 6 ani [2]. În studiul prezent, la vârsta de 5 ani, fiecare copil a prezentat aproximativ 5 molari temporari şi peste 9 suprafeţe afectate de carie, ceea ce denotă o carioactivitate crescută. Gray şi colab. (1991) [13] subliniază că prezenţa a 3 sau a mai multor molari temporari la 5 ani reprezintă cel mai bun predictor pentru apariţia cariei pe molarul unu permanent la 7 ani, iar Steineret şi colab. (citaţi de Baginska şi colab., 2014 [8]) susţin că un număr mic de molari temporari indemni de carie la 7-8 ani determină un risc carios mare în dentiţia permanentă.

Din punctul de vedere al severităţii leziunilor carioase, din totalul de 748 de molari temporari examinaţi, mai mult de jumătate $(52,67 \%)$ aveau leziuni carioase. Dintre aceştia, $61,42 \%$ au prezentat carii simple, iar 38,57\% - carii complicate. Aceste rezultate pot fi explicate prin faptul că părinţii copiilor aleg să apeleze la medicul stomatolog mai târziu, de obicei în jurul vârstei de 3-4 ani, atunci când sunt deja prezente leziuni carioase avansate. Rezultate similare s-au găsit şi în studiul realizat de Kalantari şi colab. (2014), în care prevalenţa cariilor cavitare la nivelul molarilor temporari a fost de 63,4\% [14], precum şi într-un studiu realizat de Abdullah şi colab. (2005), în care $70 \%$ dintre molarii temporari erau cariaţi [15]. Honcola şi colab. (2011) au găsit la copiii estonieni de 7-8 ani procente ridicate de carii cavitare în dentină, mai ales la molarii 2 temporari [16]. Şi Baginska şi colab. (2014) au constatat că, la 7-8 ani, cariile pe molarii temporari au fost cel mai frecvent cavitare, 26,4\% fiind însă complicate [8]. Zhang şi colab. (2014) au raportat o prevalenţă a cariei complicate pe molarii temporari de $49 \%$ la 5 ani, 18\% fiind cu gangrenă complicată [10].

În privinţa topografiei leziunilor carioase, s-a observat că cea mai afectată a fost zona ocluzo- proximală $(51,01 \%)$, urmată de suprafaţa ocluzală $(18,78 \%)$. Resturile radiculare au avut o frecvenţă de $11,42 \%$. Rezultate asemănătoare s-au obţinut şi într-un studiu realizat pe 100 de copii cu vârste cuprinse între 5 şi 7 ani, în Varna, Bulgaria, în care $81,5 \%$ dintre leziunile carioase ale molarilor temporari se aflau la nivelul suprafețelor aproximale, iar $19,5 \%$ dintre acestea pe suprafaţa ocluzală (Dimitrov şi colab., 2017) [17]. Elfrink şi colab. (2006) arată că,până la 5 ani, suprafaţa ocluzală pare a fi cea mai vulnerabilă, după această vârstă predominând cariile proximale, mai ales pe molarii unu temporari [3]. Mejare şi colab. (2000) au constatat că $64 \%$ dintre copiii de 9 ani aveau carii pe una sau mai multe feţe distale ale molarilor 2 temporari [18]. Skeie şi colab.(2004) susţin că leziunile carioase proximale la molarii temporari sunt cele mai frecvente, majoritatea fiind deja în dentină. De asemenea, susţin că 2 suprafeţe cariate pe molarii 2 temporari la vârsta de 5 ani arată că, în următorii 5 ani, vor apărea noi leziuni carioase, impunându-se, astfel, controalele periodice [19]. Toate acestea pot fi explicate prin strângerea punctelor de contact pe zona laterală începând cu 5 ani, prin igiena dificil de realizat în perioada dentiţiei mixte, prin faptul că, după vârsta de 6 ani, copiii încep să devină independenţi şi, deci, mai greu de supervizat la periaj, dar şi cu o creştere a numărului de gustări, de obicei dulci, între mese, mai ales în compania colegilor de şcoală (Moynihan, 2000 [20], Overby şi colab., 2002, citaţi de Skeie şi colab. în 2004 [19]).

Molarii 2 temporari de la ambele arcade au fost mai afectaţi decât molarii unu, cu o interesare mai mare a dinţilor inferiori. Wyne (2008) [11] a găsit o prevalenţă a cariei pe M2temp inf de 54,3\%, cea de pe M1temp inf fiind de $41,7 \%$ şi cea de pe M2temp sup de 38,9\%. Zhang şi colab. (2014) [10] au constatat că cele mai severe carii au fost pe M2temp, prevalenţa la acest nivel fiind de 52\% faţă de 37\% pe M1 temp. Şi Elfrink şi colab. (2006) au găsit că M2temp au avut indicele dmf-s semnificativ statistic mai mare decât M1temp, diferenţa venind din cariile ocluzale [3]. Studii efectuate în Ungaria, Finlanda, Japonia sau SUA susţin acelaşi lucru. Explicaţia afectării mai mari a M2 faţă de M1 poate veni din anatomia dintelui, din retenţia mai mare de placă la nivelul M2 situat mai distal şi prin interesarea mai frecventă a M2 cu defecte de structură [3]. Mosha şi colab. (1989) [21] şi Baginska şi colab. (2014) [8] au raportat însă că M1 temp inf a fost mai afectat. 
Despre tratamentele realizate pentru leziunile carioase complicate, s-a putut observa faptul că, în studiul prezent, s-au ales metode adaptate tipului de îmbolnăvire pulpară, stadiului de dezvoltare a dintelui şi gradului de cooperare cu pacientul. Pentru tratamentul pulpitelor, s-au utilizat în special tehnici conservatoare, frecvent devitale. Pentru tratamentul gangrenelor la dinţii în stadiul II, a fost preferat tratamentul conservator, pe când la dinţii stadiul III, extracţia a fost cea mai folosită atitudine terapeutică. Acest lucru a fost arătat şi într-un studiu realizat de Smaïl-Faugeron şi colab. în 2018, pe 7.140 de dinţi temporari aleşi aleatoriu, în care cea mai de succes utilizată atitudine terapeutică a fost cea conservatoare [22]. Într-un studiu efectuat în Polonia, publicat în 2014, se arată că, dintre copiii de 7 ani studiaţi, 16,4\% necesitau tratament endodontic pe DT, iar 41,9\% extracţie [8]. Skeie şi colab. (2004) au raportat că necesarul de tratament pe dinţii temporari în perioada 5-10 ani este mare [19], iar Alm şi colab. (2003) au obţinut că majori-

\section{$\overline{\text { BIBLIOGRAFIE }}$}

1. Saravanan S, Madivanan I, Subashini B et al. Prevalence pattern of dental caries in the primary dentition among school children. Indian J Dent Res. 2005;16:140-5.

2. Kashetty MV, Patil S, Kumbhar S et al. Prevalence of dental caries among 3-6 year old Anganwadi children in Mudhol town, Karnataka, India. J Indian Assoc Public Health Dent. 2016;14:403-8.

3. Elfrink MEC, Veerkamp JSJ, Kalsbeek H. Caries pattern in primary molars in Dutch 5-year-old children. Eur Arch Paed Dent. 2006; 7(4):236-40.

4. Luca R. Pedodonţie, vol. 2. Editura Cermaprint, Bucureşti, 2003:33-42;99-120.

5. Chandramohan S. A study on prevalence of early childhood caries among children attending Anganwadi center in Udupitaluk, Karnataka. Online Int Interdiscip Res J. 2014;4:248-52.

6. Jose B, King NM. Early childhood caries lesions in preschool children in Kerala, India. Pediatr Dent. 2003;25:594-600.

7. Azizi Z. The prevalence of dental caries in primary dentition in 4- to 5-year-old preschool children in northern Palestine. Int J Dent. 2014; 2014:839419.

8. Baginska J, Rodakowska E, Milewski R et al. Dental caries in primary and permanent molars in 7-8-year-old schoolchildren evaluated with Caries Assessment Spectrum and Treatment (CAST) index. BMC Oral Health. 2014;14:74.

9. Matulaitiene ZK, Zemaitiene M, Zemgulyte $S$ et al. Changes in dental caries and oral hygiene among 7-8-year-old schoolchildren in different regions of Lithuania 1983-2009. Stomatologija Baltic Dental and Maxillofacial J. 2012;14(53):59-59.

10. Zhang S, Liu J, Lo ECM et al. Dental caries status of Dai preschool children in Yunnan Provence. China. BMC Oral Health. 2014;14:16.

11. Wyne AH. Caries prevalence, severity and pattern in preschool children. J Contemp Dent Pract. 2008;9:24-31.

12. Chandan GD, Saraf S, Sangavi N, Khatri A. Pattern of dental caries in 3-6-year-old children using decayed, missing, filled surface index and hierarchical caries pattern system: A descriptive study. J Ind Soc Pedod Prev Dent. 2018;36(2):108-12. tatea tratamentelor pe DT au fost făcute după 6 ani, mai ales între 7 şi 9 ani [23]. Raadal şi colab. (2002) recomandă ca tratamentul la copiii preşcolari şi şcolari să se realizeze în şedinţe scurte, cu multă răbdare şi blândeţe, pentru a evita apariţia anxietăţii dentare la adult [24].

\section{CONCLUZII}

Prevalenţa crescută a cariei complicate la molarii temporari şi valorile mari ale indicilor de experienţă carioasă indică necesitatea prezentării timpurii la cabinetul stomatologic a copiilor. Este importantă aplicarea, pe cât posibil, a tratamentelor de tip conservator la molarii temporari cu carii complicate pentru a-i menţine pe arcadă cât mai aproape de perioada fiziologică de exfoliere.

\section{Notă}

Autorii au contribuit în mod egal la prezentul articol, de aceea toţi sunt consideraţi autori principali.

Conflict of interest: none declared Financial support: none declared

13. Gray MM, Marchment MD, Anderson RJ. The relationship between caries experience in the deciduous molars at 5 years and in first permanent molars of the same child at 7 years. Community Dent Health. 1991;8:3-7.

14. Kalantari B, Rahmannia J, Hossein Hatami H et al. The prevalence of dental caries in primary molars and its related factors in 6 and 7 years old children in Shemiranat health center. Journal of Health in the Field. 2014;1(4):2.

15. Abdullah S, Qazi HS, Maxood A. Dental caries status in 6-9 years old children. Pak Oral Dent J. 2005;28(1):107-12.

16. Honcala E, Runnel R, Honkala $S$ et al. Measuring dental caries in the mixed dentition by ICDAS. Int J Dent. 2011:50424.

17. Dimitrov E, Georgieva M, Andreeva R et al. Caries prevalence among 5-7 years-old children in northeast Bulgaria. Journal of IMAB. 2017;23(3):1633-6.

18. Mejare I, Stenlund $H$. Caries rates for the mesial surface of the first permanent molar and the distal surface of the second primary molar from 6 to 12 years of age in Sweden. Caries Res. 2000;34(6):454-61.

19. Skeie MS, Raadal M, Strand GV et al. Caries in primary teeth at 5 and 10 years of age: a longitudinal study. Eur J Paed Dent. 2004; 4:194-202.

20. Moynihan P. The British Nutrition Foundation Oral Task Force report - issues relevant to dental health professionals. Br Dent J. 2000; 188(6):308-12.

21. Mosha HJ, Robison VA. Caries experience of the primary dentition among groups of Tanzanian urban pre-school children. Community Dent Oral Epidemiol. 1989;17:34-7.

22. Smaïl-Faugeron V, Glenny AM, Courson F, Durieux P, Muller-Bolla $M$, Fron Chabouis H. Pulp treatment for extensive decay in primary teeth. Cochrane Database Syst Rev. 2018;5(5):CD003220.

23. Alm A, Wendt LK, Koch G. Dental treatment in the primary dentition of 7-12 year-old Swedish schoolchildren. Swed Dent J. 2003; 27(2):77-82.

24. Raadal M, Strand GV, Amarante EC et al. Relationship between caries prevalence at 5 years of age and dental anxiety at 10 . Eur $J$ Paediatr Dent. 2002;3(1):22-6. 